\title{
Computational investigation of contraction behavior in a liquid-solid fluidized bed
}

\author{
Yao Xiuying1, Guan Yanjun', Chang Jian², Zhang Kai ${ }^{1,2 *}$ and Jiang \\ Jianchun $^{3}$ \\ ${ }^{1}$ State Key Laboratory of Heavy Oil Processing, China University of Petroleum, Beijing 102249, China \\ ${ }^{2}$ National Engineering Laboratory for Biomass Power Generation Equipment, North China Electric Power University, Beijing \\ 102206, China \\ ${ }^{3}$ National Engineering Laboratory for Biomass Chemical Utilization, Institute of Chemical Industry of Forest Products, Chinese \\ Academy of Forestry, Nanjing 210042, China
}

(C) China University of Petroleum (Beijing) and Springer-Verlag Berlin Heidelberg 2012

\begin{abstract}
Contraction behavior of a liquid-solid fluidized bed has been investigated numerically. Based on a simple hydrodynamic model proposed by Brandani and Zhang (2006), a case study for solid particles with a density of $3,000 \mathrm{~kg} / \mathrm{m}^{3}$ and a diameter of $2.5 \times 10^{-3} \mathrm{~m}$ is simulated in a two-dimensional fluidized bed $(0.50 \mathrm{~m}$ height and $0.10 \mathrm{~m}$ width). Due to the continuity of numerical computation, there is a transition region between two zones of different solid holdups when the liquid velocity is suddenly changed. The top, middle and bottom interfaces are explored to obtain a reasonable interface height. The simulated results show that the steady time of the middle interface is more close to Gibilaro's theory and suitable for describing the contraction process of a phase interface. Furthermore, the effect of liquid velocity and particle diameter is simulated in the other two-dimensional fluidized bed $(0.10 \mathrm{~m}$ height and $0.02 \mathrm{~m}$ width) where the solid particles are glass beads whose properties are similar to those of the catalyst particles used in the alkylation process. The results also show good agreement with Gibilaro's theory, and that larger particles lead to a more obvious bed contraction.
\end{abstract}

Key words: Liquid fluidized bed, dynamic bed contraction, CFD simulation

\section{Introduction}

With increasingly stringent environmental protection policies, the production of gasoline with high octane value, low olefins, and low sulfur content poses a great challenge to the oil refining industry of China. To meet this challenge, novel catalysts and processes for producing clean fuel have been proposed, e.g., the Hydrodesulfurization (HDS) and C4 alkylation processes (Chang et al, 2009).

HDS is a commonly used method for sulfur reduction of petroleum in refineries (Guo et al, 2010). However, this process will cause a significant reduction of octane number due to the saturation of olefins in naphtha from fluid catalytic cracking, as well as the high hydrogen consumption (Song, 2003). On the other hand, alkylate is one of the few components that seems to avoid such restrictions (Hommeltoft, 2001; Meister et al, 2000) due to its low volatility, reactivity and toxicity (Platon and Thomson, 2005). The alkylation process is thus a promising method to produce clean gasoline.

At present, development of an alkylation process using

*Corresponding author. email: kzhang@ncepu.edu.cn

Received May 24, 2011 solid catalyst is one of the most challenging aspects in improving the production of a "green" gasoline component (Nieto et al, 2007). Many investigations of catalysts and reactors for the alkylation process have been reported (Arias et al, 2008; Hu et al, 2009; Li et al, 2010; Pan et al, 2007; Tailleur, 2008; Wang et al, 2003). Pan et al (2007) synthesized a new type of zeolite catalyst and evaluated its performance in a fixed-fluidized bed. Tailleur (2008) investigated flow behavior of gas-liquid-solid three-phase system for solid catalyst alkylation in a spouted-bed reactor. $\mathrm{Hu}$ et al (2009) compared the reaction performance of five LaHY zeolites with different particle sizes. Recently, Li et al (2010) synthesized a high-silica $\mathrm{NaY}$ zeolite with $\mathrm{Si} / \mathrm{Al}$ ratio higher than 2.5 from kaolin and investigated the influence of synthesis variables on the crystallinity and $\mathrm{Si} / \mathrm{Al}$ ratio of $\mathrm{NaY}$ zeolite. However, less attention has been paid to the fluidization characteristics of catalyst particles in the alkylation process using a liquidsolid fluidized bed as the reactor. As reported by Wang et al (2003), the distributions of the solid velocity and solid holdup are of importance for the alkylation process in the liquid-solid fluidized bed. For design and optimization of the alkylation process, it is necessary to understand the spatio-temporal hydrodynamics of the liquid-solid fluidized bed. This paper focuses on the dynamic contraction process in the liquid- 
solid fluidized beds by computational fluid dynamics (CFD) method based on a simple hydrodynamic model.

\section{CFD model}

\subsection{Governing equations and simulation method}

In general, there are two different models for simulating the hydrodynamics in a liquid-solid fluidized bed, i.e., Eulerian-Lagrangian model and Eulerian-Eulerian model. In the Eulerian-Lagrangian model, solid phase is regarded as a discrete phase, and fluid phase is regarded as a continuous phase. As it tracks each particle individually, this model is too complicated to apply to an engineering installation at the present technical state (Knowlton et al, 2005). The EulerianEulerian model describes both the solid and liquid phases as interpenetrating continua, and is superior to EulerianLagrangian model, because it can reduce the computational time and handle large industrial scale geometries (Patil et al, 2005a). However, the role and model of the solid phase viscosity and solid phase pressure gradient in the solid momentum equations have been debated by many researchers (such as Li et al, 2005; Patil et al, 2005b; and Zhang et al, 2005).

In previous studies, a particle-bed model (PBM) was proposed to investigate fluid dynamic stability in onedimensional fluidized beds by Foscolo and Gibilaro (1987). Chen et al (1999) then extended it further to a two-dimensional form that can qualitatively predict the fluidization quality in both gas- and liquid-fluidized systems. In the classical PBM, the effect of particle movement on the gas momentum balance was ignored. In recent years, a model starting from the finite formulation of the two-fluid theory as well as consideration of particle-fluid interactions under a quasi-equilibrium state has been proposed by Zhang et al (2005) and Brandani and Zhang (2006). Later, Pei et al (2009) and Wang et al (2011) respectively applied this model to investigate the bubbling/collapsing characteristics and pressure fluctuation behavior in a gas-solid fluidized bed. A detailed derivation of the model can be found in the literature (Brandani and Zhang, 2006), and it is briefly summarized below.

The continuity and momentum balance equations, describing liquid and particle flows in the two-dimensional cold model of fluidized bed, are given below:

Continuity equations

Liquid phase

$$
\frac{\partial \varepsilon_{1}}{\partial t}+\nabla \cdot\left(\varepsilon_{1} \vec{u}_{1}\right)=0
$$

Solid phase

$$
\frac{\partial \varepsilon_{\mathrm{s}}}{\partial t}+\nabla \cdot\left(\varepsilon_{\mathrm{s}} \vec{u}_{\mathrm{s}}\right)=0
$$

\section{Momentum equations}

Liquid phase

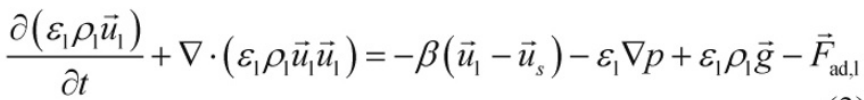

Solid phase

$\frac{\partial\left(\varepsilon_{\mathrm{s}} \rho_{\mathrm{s}} \vec{u}_{\mathrm{s}}\right)}{\partial t}+\nabla \cdot\left(\varepsilon_{\mathrm{s}} \rho_{\mathrm{s}} \vec{u}_{\mathrm{s}} \vec{u}_{\mathrm{s}}\right)=-\beta\left(\vec{u}_{\mathrm{s}}-\vec{u}_{1}\right)-\varepsilon_{\mathrm{s}} \nabla p+\varepsilon_{\mathrm{s}} \rho_{\mathrm{s}} \vec{g}-\vec{F}_{\text {ad, } \mathrm{s}}$

where $\varepsilon$ represents the volume fraction $\left(\varepsilon_{1}+\varepsilon_{\mathrm{s}}=1\right), \vec{u}$ is the velocity vector, $\vec{F}_{\text {ad }}$ is the additional force and $\rho$ is the density. The subscripts 1 and $\mathrm{s}$ indicate liquid and solid phases, respectively. The terms on the right-hand side of Eqs. (3) and (4) are respectively interphase drag, pressure drop, gravity, and additional force resulting from the discrete nature of the fluidized particles. According to the closure principles of governing equations, interphase drag coefficient $\beta$ and additional forces, $\vec{F}_{\text {ad,l }}$ and $\vec{F}_{\text {ad.s }}$, need to be derived from the above basic variables. Their vector expression is as follows, respectively:

$$
\begin{aligned}
& \vec{F}_{\mathrm{ad}, \mathrm{l}}=d_{\mathrm{s}}\left[\left(1-2 \varepsilon_{1}\right) \rho_{\mathrm{s}}+2 \varepsilon_{1} \rho_{\mathrm{l}}\right] \vec{g} \cdot \nabla \varepsilon_{1} \vec{i} \\
& \vec{F}_{\mathrm{ad}, \mathrm{s}}=d_{\mathrm{s}}\left[2 \varepsilon_{\mathrm{s}} \rho_{\mathrm{s}}+\left(1-2 \varepsilon_{\mathrm{s}}\right) \rho_{1}\right] \vec{g} \cdot \nabla \varepsilon_{1} \vec{i}
\end{aligned}
$$

where $\vec{i}$ is unit vector, which is the same direction as acceleration due to gravity, $\vec{g}$.

The interphase drag coefficient, $\beta$, is a function of the particle drag coefficient, $C_{\mathrm{D}}$.

$$
\beta=C_{D} \frac{3 \varepsilon_{\mathrm{s}} \rho_{1}\left|\left(\vec{u}_{\mathrm{s}}-\vec{u}_{1}\right)\right|}{4 d_{\mathrm{s}}} \varepsilon_{1}^{-1.8}
$$

and the particle drag coefficient, $C_{\mathrm{D}}$, can be obtained from the empirical Dallavalle relationship (Gibilaro, 2001).

$$
C_{D}=\left(0.63+\frac{4.8}{\sqrt{\operatorname{Re}}}\right)^{2}
$$

where

$$
R e=\frac{\varepsilon_{1} \rho_{1}\left|\vec{u}_{1}-\vec{u}_{\mathrm{s}}\right| d_{\mathrm{s}}}{\mu_{1}}
$$

Numerical calculation is performed on the platform of a commercial CFD code, CFX4.4. More details can be found in previous papers (Zhang et al, 2005; Brandani and Zhang, 2006; Pei et al, 2009; Wang et al, 2011).

\subsection{Simulation system}

With the purpose of studying the contracting process, two 2D liquid-solid fluidized beds and two different particles (see Table 1) are used in this work. All the experiments are conducted at ambient conditions. Three methods, i.e. top interface, middle interface and bottom interface (as explained in Section 3.2), are examined to determine the interface of the transition region by comparison with the theoretical predictions of the system A. Then, the middle interface method is applied to analyze the contracting process of the spherical glass beads in the system B (Wang et al, 2003). 
Table 1 Main parameters of the two systems

\begin{tabular}{|c|c|c|}
\hline System & A & B \\
\hline Bed size (height $\times$ width), $\mathrm{m}^{2}$ & $0.50 \times 0.10$ & $0.10 \times 0.02$ \\
\hline \multicolumn{3}{|l|}{ Liquid properties } \\
\hline Viscosity, $\mathrm{Pa} \cdot \mathrm{s}$ & \multicolumn{2}{|c|}{$1.0 \times 10^{-3}$} \\
\hline Density, $\mathrm{kg} / \mathrm{m}^{3}$ & \multicolumn{2}{|c|}{1000} \\
\hline \multicolumn{3}{|l|}{ Solid properties } \\
\hline Diameter, $\mathrm{m}$ & $2.5 \times 10^{-3}$ & $1.75 \times 10^{-4}$ \\
\hline Density, $\mathrm{kg} / \mathrm{m}^{3}$ & 3000 & 2460 \\
\hline \multicolumn{3}{|l|}{ Initial and operating conditions } \\
\hline Initial bed height, $\mathrm{m}$ & 0.42 & 0.059 \\
\hline Initial solids packing & 0.26 & 0.29 \\
\hline Initial liquid velocity, $\mathrm{m} / \mathrm{s}$ & 0.14 & 0.0040 \\
\hline Mesh number & \multicolumn{2}{|c|}{$100 \times 20$} \\
\hline Time step, s & \multicolumn{2}{|c|}{0.001} \\
\hline
\end{tabular}

Initially the system A with static bed height $0.42 \mathrm{~m}$ is fluidized at a liquid velocity of $0.14 \mathrm{~m} / \mathrm{s}$ and solid holdup of 0.26 . For the system $B$, the initial configuration is characterized by a static bed height of $0.059 \mathrm{~m}$ and solid holdup of 0.29 , and the operation velocity is $0.0040 \mathrm{~m} / \mathrm{s}$, which is much greater than $2.66 \times 10^{-4} \mathrm{~m} / \mathrm{s}$ predicted by the classical Ergun equation. Pressure profile is calculated from the hydrostatic bed height based on the reference pressure (atmospheric) as below:

$$
\begin{array}{ll}
p=p_{0}+\left(H_{\mathrm{t}}-H_{0}\right) \rho_{1} g+\rho_{\mathrm{ave}} g\left(H_{0}-z\right) \quad\left(\mathrm{z} \leq H_{0}\right) \\
p=p_{0}+\rho_{1} g\left(H_{\mathrm{t}}-z\right) & \left(\mathrm{z}>H_{0}\right) \\
\rho_{\text {ave }}=\rho_{\mathrm{s}} \varepsilon_{\mathrm{s}}+\rho_{1} \varepsilon_{1} &
\end{array}
$$

where $H_{0}$ and $H_{\mathrm{t}}$ are static bed height and total bed height, respectively. $z$ stands for vertical direction. The volume fraction of solid $\left(\varepsilon_{\mathrm{s}}\right)$ should be zero above bed surface. However, $\varepsilon_{\mathrm{s}}$ is set to $10^{-10}$ during the practical computational procedure, so as to provide more realistic results for the particle velocity and good convergence.

The initial static bed is impulsively fluidized with a uniform liquid superficial velocity at the bottom of the bed. At the inlet, the liquid velocity in the horizontal direction is set to zero, and so does the particle velocity in the horizontal and vertical directions. At the top of the bed, a pressure outlet (ambient atmosphere) is assumed. Left and right boundaries are treated as impermeable and rigid walls, where the no-slip velocity boundary conditions are employed for both liquid and solid phases and the effects of the front and back walls are neglected.

\section{Results and discussion}

\subsection{Prediction for response time}

Fig. 1 shows the transient response of the homogeneous fluidized bed. The transient response time can be predicted as follows as changing the fluid velocity. When the fluidizing velocity decreases from $U_{1}$ to $U_{2}$, solid holdup and bed height change from the initial values $\varepsilon_{\mathrm{s} 1}$ and $L_{1}$ to the final steady state values $\varepsilon_{\mathrm{s} 2}$ and $L_{2}$, respectively. During the transient period, both the total bed height $L_{\mathrm{B}}$ and the interface height $L_{\mathrm{I}}$ separated the two zones are related to time. The liquid velocity in the lower zone is $U_{2}$, and in the upper zone is determined as $U_{\mathrm{A}}$. When the liquid velocity is suddenly increased, the lower zone of fluidized bed grows at a rate of $d L_{\mathrm{I}} / d \mathrm{t}$. The rate of liquid change in this growing zone is $\left(\varepsilon_{l 2}-\varepsilon_{l 1}\right) \mathrm{d} L_{I} / \mathrm{d} t$. The mass balance for fluid in this region is obtained as below:

$$
U_{2}-U_{\mathrm{A}}=\left(\varepsilon_{l 2}-\varepsilon_{l 1}\right) \frac{\mathrm{d} L_{I}}{\mathrm{~d} t}
$$

where $U_{\mathrm{A}}$ is the liquid velocity, which can maintain equilibrium conditions in the upper zone during the transient response period. As the liquid holdup $\varepsilon_{l 1}$ remains unchanged, the relative velocity between liquid and particles also remains constant. The liquid and particle velocities are $U_{\mathrm{A}} / \varepsilon_{l 1}$ and $d L_{\mathrm{s}} / d \mathrm{t}$, respectively, which results in:

$$
\frac{U_{\mathrm{A}}}{\varepsilon_{l 1}}-\frac{\mathrm{d} L_{\mathrm{B}}}{\mathrm{d} t}=\frac{U_{1}}{\varepsilon_{l 1}}
$$

By combining Eqs. (13) and (14), an equation linking the two interface velocities are obtained:

$$
\varepsilon_{l 1} \frac{\mathrm{d} L_{\mathrm{B}}}{\mathrm{d} t}+\left(\varepsilon_{l 2}-\varepsilon_{l 1}\right) \frac{\mathrm{d} L_{I}}{\mathrm{~d} t}=U_{2}-U_{1}
$$

During the process, it is assumed that the balance around the solid volume in the fluidized bed can be written as follows:

$($ Total solid volume $)=($ Solid volume in lower zone $)+$ (Solid volume in upper zone)

$$
V_{\mathrm{B}}=\varepsilon_{\mathrm{s} 2} L_{I}+\varepsilon_{\mathrm{s} 1}\left(L_{\mathrm{B}}-L_{I}\right)=\varepsilon_{\mathrm{s} 1} L_{\mathrm{B}}+\left(\varepsilon_{\mathrm{s} 2}-\varepsilon_{\mathrm{s} 1}\right) L_{I}
$$

Clearly, $\mathrm{d} V_{\mathrm{B}} / \mathrm{d} t$ is zero as $V_{\mathrm{B}}$ remains constant, so that Eq. (16) can be expressed as:

$$
\varepsilon_{\mathrm{s} 1} \frac{\mathrm{d} L_{\mathrm{B}}}{\mathrm{d} t}-\left(\varepsilon_{\mathrm{s} 1}-\varepsilon_{\mathrm{s} 2}\right) \frac{\mathrm{d} L_{I}}{\mathrm{~d} t}=0
$$

The velocity $\left(u_{\mathrm{bs}}\right)$ at the bed surface during the transient response period can be obtained by combined Eqs. (15) and (17):

$$
u_{\mathrm{bs}}=\frac{\mathrm{d} L_{\mathrm{B}}}{\mathrm{d} t}=U_{2}-U_{1}
$$

Accordingly, following a sudden change in liquid velocity, the particles in the upper zone are predicted to travel at the constant velocity that is equal to this change. The total 
duration $\left(T_{\mathrm{T}}\right)$ of transient period follows from relation (19). Detailed derivation can be found in the literature (Gibilaro, 2001).

$$
T_{\mathrm{T}}=\frac{L_{2}-L_{1}}{U_{2}-U_{1}}
$$

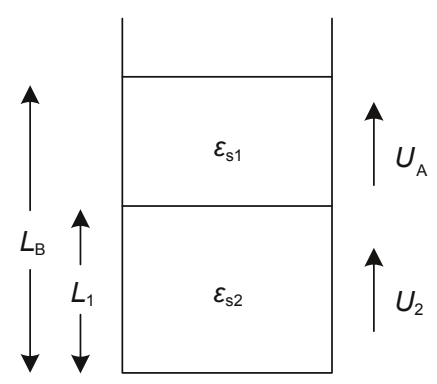

Fig. 1 Transient response of homogeneous fluidized bed

\subsection{Determination of the interface height}

In this section, the determination of the interface height during the contracting process is analyzed based on the system A. Inlet liquid velocity is suddenly reduced from 0.14 $\mathrm{m} / \mathrm{s}$ to $0.03 \mathrm{~m} / \mathrm{s}$ and correspondingly, the height of bed surface is changed from $0.42 \mathrm{~m}$ to $0.20 \mathrm{~m}$. According to Eq. (19), the characteristic time is $2.00 \mathrm{~s}$.

A sudden decrease in inlet liquid velocity creates a particle piston, which possesses two interfaces with the fluid through which it travels. The top interface of the piston (i.e. bed surface) is subjected to a small disturbance, which displaces a particle some way into the clear liquid above. The displaced particle immediately obtains a reduction in drag, which quickly returns the particle to its previous position. At the bottom interface of the piston (i.e. medium interface), a displaced particle also experiences a net downward force, which is caused by the reduction in liquid velocity below the clear fluid. Nevertheless, this effect is far from a stabilizing influence. Moreover, the effect is to drive it down further from the bottom interface at this time. The particles from adjacent locations follow the effect as they respond to the resulting increase in solid volume fraction around them. The medium interface is therefore unstable. Particles rain down from it continuously, giving rise to an upward propagating erosion of the particle piston.

When the inlet liquid velocity is decreased from $0.14 \mathrm{~m} / \mathrm{s}$ to $0.03 \mathrm{~m} / \mathrm{s}$, the step variation of solid holdup with time as the function of bed height is shown in Fig. 2. Obviously, there are two travelling interfaces: the falling surface of the bed, and the rising phase interface, which separates two zones. The whole bed will have attained a new equilibrium state when the interface meets the bed surface. During the contracting process, the propagating erosion generates a transition region between the lower zone with high solid holdup and the upper zone with low solid holdup (see Fig. 3). It is clear that the simulated transition region exhibits a gradual change in solid holdup due to the continuity of numerical computation as shown in Figs. 2 and 3, which is slightly different from the theoretical analysis in Section 3.1. Therefore, three heights are explored to determine the interface between two concentration zones (or the interface height). In this study, $h_{1}$ stands for the bottom interface height, $h_{2}$ for the top interface height and $h_{\text {ave }}$ for the average value of $h_{1}$ and $h_{2}$ (hereafter named the middle interface height).

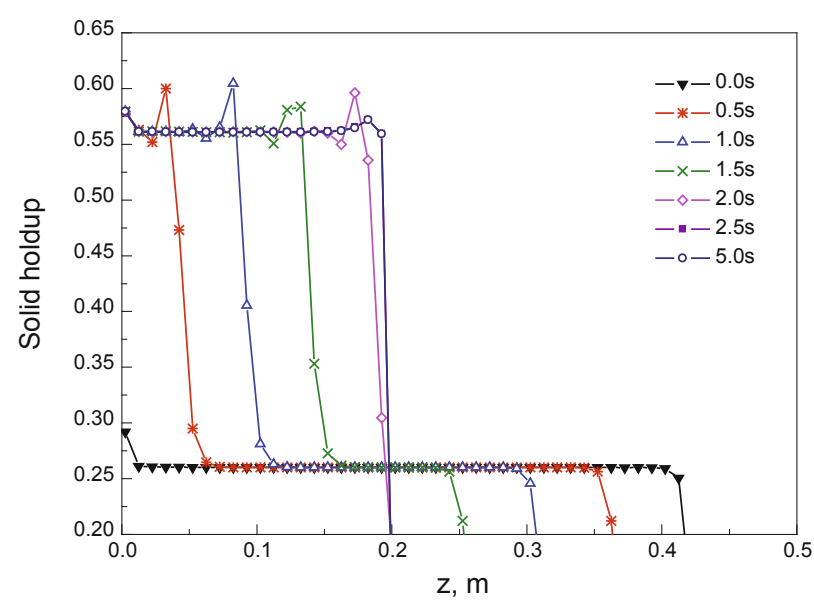

Fig. 2 Spatio-temporal evolution of solid holdup during bed contraction

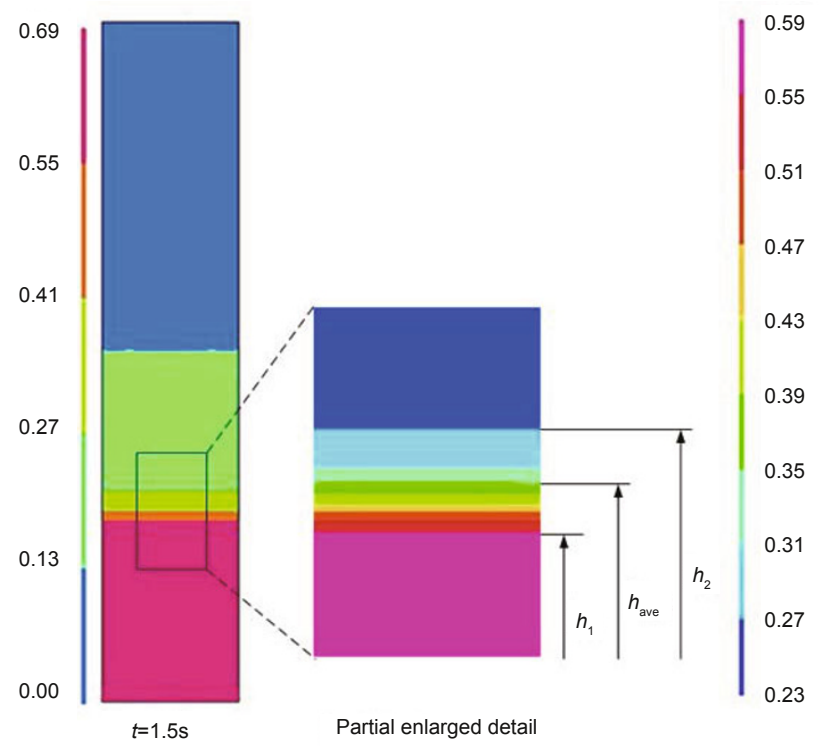

Fig. 3 A typical example of the three interface heights in the transition region

Fig. 4 shows the variation of the bed surface height and three interface heights corresponding to different solid holdups. These discrete points stand for numerical results, whilst solid lines for their fitted results. It is found that three calculated response times are $1.98 \mathrm{~s}$ for $h_{1}, 2.14 \mathrm{~s}$ for $h_{2}$, and $2.00 \mathrm{~s}$ for $h_{\text {ave }}$. Compared with theoretical value of 2.00 s (Gibilaro, 2001), $h_{\text {ave }}$ is more suitable for determining the interface height in this study.

\subsection{Bed contraction}

When a single spherical particle is at initial steady state with a liquid velocity of $0.0040 \mathrm{~m} / \mathrm{s}$, its weight is balanced by the combined buoyant and drag forces for the system B. Once 


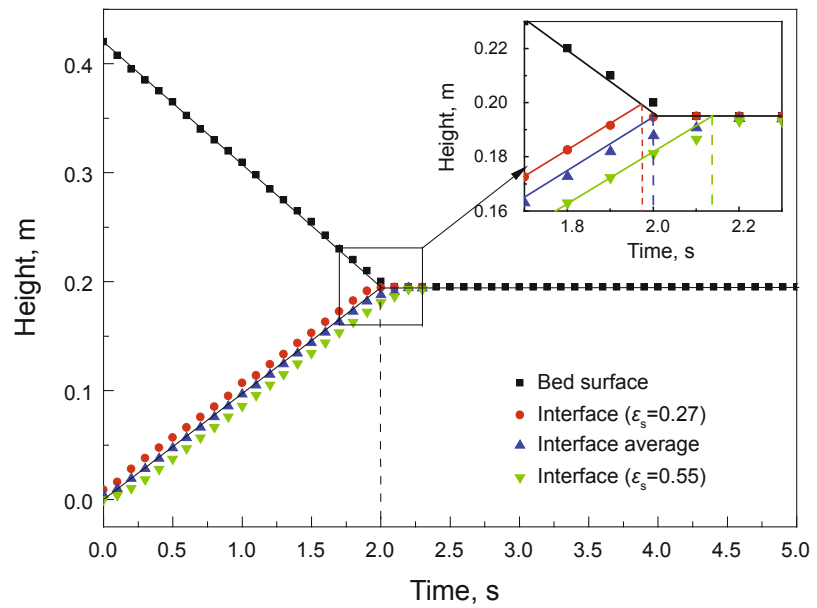

Fig. 4 Variation in bed surface height and interface height with time during bed contraction

the liquid velocity is switched to a lower value of $0.0015 \mathrm{~m} / \mathrm{s}$, the steady state is destroyed. The immediate effect of the drop in liquid velocity is to bring about a sudden reduction in drag force on all the particles, and leads to a net force causing them to accelerate downward together. At this moment, the solid holdup in upper zone has not enough time to change and maintains the original value of 0.29 . Fig. 5 qualitatively describes this dynamic response of the system B. Obviously, the overall bed consists of two regions during the contracting process. The solid holdup and velocity in the red region are 0.43 and $0.0015 \mathrm{~m} / \mathrm{s}$, respectively, and their corresponding values are 0.29 and $0.0040 \mathrm{~m} / \mathrm{s}$ in the green region. The fluidized bed reaches to a new homogeneous and steady state, after $7.6 \mathrm{~s}$, with an overall solid holdup of 0.43 and a bed surface height of $0.20 \mathrm{~m}$. Furthermore, detailed evolution of the solid holdup is quantitatively shown in Fig. 6. It is observed that the axial profile of solid holdup is a constant in the initial or final steady state, exhibiting a gradual transition of solid holdup profiles during the contracting process.

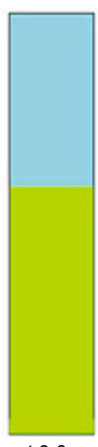

$t-0.0$ s
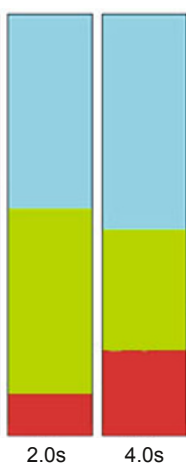
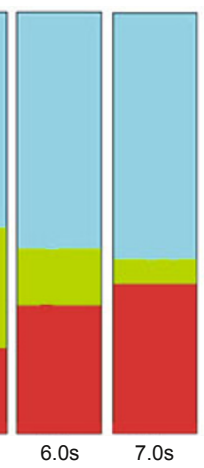
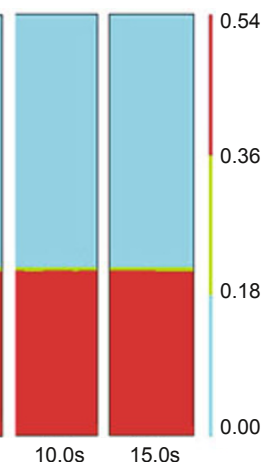

Fig. 5 Snapshots of the transient contracting process

In order to obtain the accurate interface height, an image recognition technique suggested in Section 3.2 is used to distinguish the interface. This method adopts an average value of heights corresponding to solid holdup 0.29 and 0.43 as the reference value, respectively corresponding to solid holdup at the initial and final states. Fig. 7 shows the variation of the bed surface height and middle interface height obtained

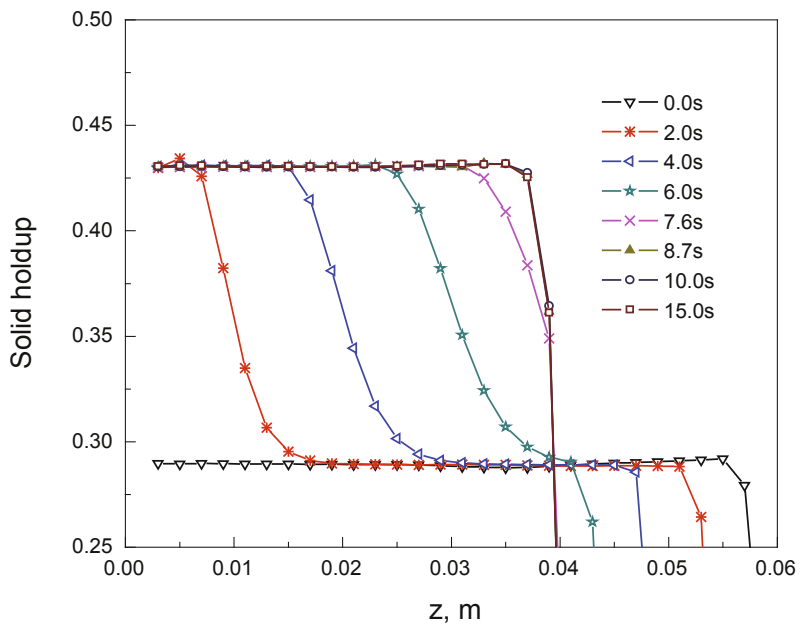

Fig. 6 Spatio-temporal evolution of solid holdup during bed contraction

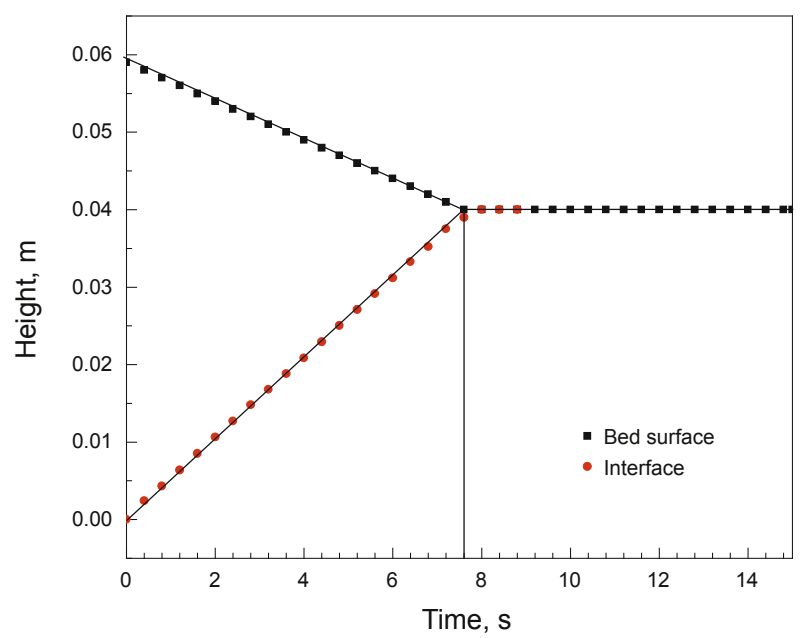

Fig. 7 Variation in bed surface height and internal interface height with time during bed contraction

by the above way. Similar to Section 3.2, the discrete points correspond to the simulated heights while the solid lines are their fitted one. During transient response, when bed surface is decreased from $0.059 \mathrm{~m}$ to $0.040 \mathrm{~m}$ step by step, the middle interface is gradually increased from $0 \mathrm{~m}$ to $0.040 \mathrm{~m}$. According to Gibilaro's theory, the response time is about 7.6 $\mathrm{s}$, which is equal to the simulated value in this study.

\subsection{The effect of particle diameter}

In order to investigate the effect of particle diameter on the contraction behavior, the particle size is increased from $1.75 \times 10^{-4} \mathrm{~m}$ to $2.50 \times 10^{-4} \mathrm{~m}$ based on the system $\mathrm{B}$. The liquid velocity is fixed at $0.0040 \mathrm{~m} / \mathrm{s}$ as the inlet boundary. It is found from Fig. 8 that solid holdup starts to increase from the bottom of the bed at a rapid rate at the beginning stage of the dynamic process, whereas there is no change in the upper zone. A new equilibrium state is achieved after $5.2 \mathrm{~s}$. Similar to the bed contracting process by decreasing the inlet liquid velocity, there is also a particle piston, i.e., a falling bed surface and a rising interface, during the transient period. The main reason is that both gravity and buoyancy acting on the 


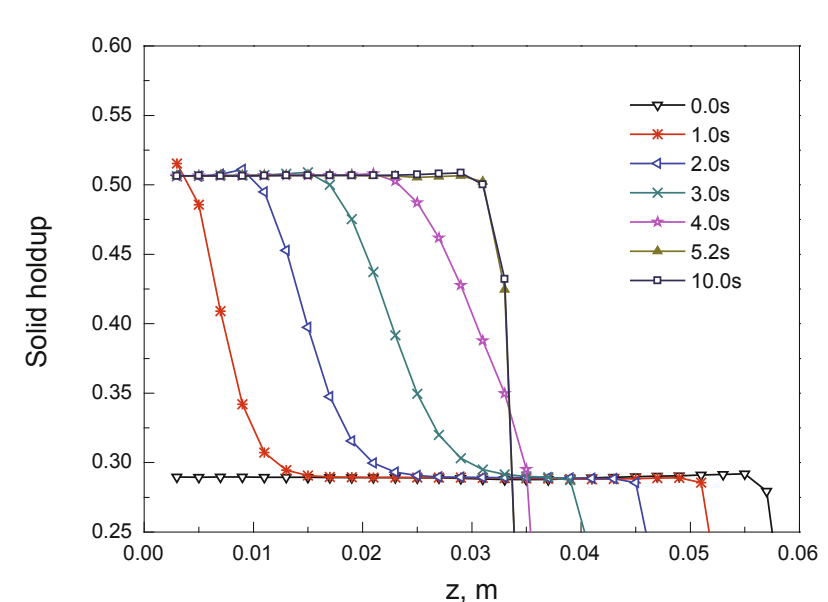

Fig. 8 Spatio-temporal evolution of solid holdup

particles increase with increasing particle diameter. However, the effect of gravity is more significant than that of buoyancy, resulting in particles being accelerated downward and a final decrease of the bed height.

\section{Conclusions}

The dynamic contraction behaviors, such as the solid holdup profile and the bed surface and interface, are investigated in two liquid solid fluidized beds by using a simple hydrodynamic model proposed by Brandani and Zhang (2006). In view of the above results, the following conclusions are obtained:

1) There is a transition region between two main contraction zones during the bed contracting process. Three methods, including the top interface method, the middle interface method and the bottom interface method, are explored to distinguish the phase interface. The computational data confirm the middle interface method is suitable for determining this interface by compared with Gibilaro's theory.

2) When liquid velocity is decreased, the drag force on each glass bead reduces, which leads to downward acceleration of all particles and bed contraction. The simulated response time obtained by the middle interface method is in good agreement with Gibilaro's theory.

3) When particle diameter is changed, larger particle diameter gives rise to greater gravity and buoyancy. The particles also accelerate downward as the gravity plays a dominant role in this process. Compared with small particles, larger particles lead to a more obvious bed contraction.

\section{Nomenclatures}

$\begin{array}{ll}C_{\mathrm{D}} & \text { Particle drag force coefficient } \\ d_{\mathrm{s}} & \text { Solid diameter, } \mathrm{m} \\ \vec{F}_{\text {ad }} & \text { Additional force, } \mathrm{N} / \mathrm{m}^{3} \\ \vec{g} & \text { Acceleration due to gravity, } \mathrm{m} / \mathrm{s}^{2}\end{array}$

$\begin{array}{ll}H_{0} & \text { Static bed height, } \mathrm{m} \\ H_{\mathrm{t}} & \text { Total bed height, } \mathrm{m} \\ H & \text { Interface height of transition region, } \mathrm{m} \\ \vec{i} & \text { Unit vector } \\ L & \text { Bed surface height, } \mathrm{m} \\ L_{\mathrm{B}} & \text { Total height of bed, } \mathrm{m} \\ L_{\mathrm{I}} & \text { Interface height, } \mathrm{m} \\ P & \text { Pressure, } \mathrm{N} / \mathrm{m}^{2} \\ p_{0} & \text { Atmospheric pressure, } \mathrm{N} / \mathrm{m}^{2} \\ R e & \text { Reynolds number } \\ T & \text { Time, } \mathrm{s} \\ T_{\mathrm{T}} & \text { Total lasting time in a transient period, } \mathrm{s} \\ \vec{u} & \text { Velocity vector, } \mathrm{m} / \mathrm{s} \\ u_{\mathrm{bs}} & \text { Bed surface height in a transient period, } \mathrm{m} / \mathrm{s} \\ U & \text { Velocity, } \mathrm{m} / \mathrm{s} \\ U_{\mathrm{A}} & \text { Liquid velocity in the top zone, } \mathrm{m} / \mathrm{s} \\ V_{\mathrm{B}} & \text { Total solid volume, } \mathrm{m} \\ Z & \text { Vertical direction, } \mathrm{m}\end{array}$

\section{Greek letters}

$\beta \quad$ Interphase drag coefficient

$\varepsilon \quad$ Holdup

$\mu \quad$ Viscosity, $\mathrm{Pa} \cdot \mathrm{s}$

$\rho \quad$ Density, $\mathrm{kg} / \mathrm{m}^{3}$

\section{Subscripts}

$\begin{array}{ll}\text { Ave } & \text { Average value } \\ 1 & \text { Liquid phase } \\ \mathrm{S} & \text { Solid phase } \\ 1,2 & \text { Two different states }\end{array}$

\section{Acknowledgements}

Financial support from the National Natural Science Foundation of China (20976191 and 51025624), Program for New Century Excellent Talents in University (NCET-090342), and 111 Project (B12034) is gratefully acknowledged.

\section{References}

Arias M, Laurenti D, Bellière V, et al. Preparation of supported $\mathrm{H}_{3} \mathrm{PW}_{12} \mathrm{O}_{40} \cdot 6 \mathrm{H}_{2} \mathrm{O}$ for thiophenic compounds alkylation in $\mathrm{FCC}$ gasoline. Applied Catalysis A: General. 2008. 348(1): 142-147

Brandani S and Zhang K. A new model for prediction of the behaviour of fluidized bed. Powder Technology. 2006. 163(1-2): 80-87

Chang J, Gao J S and Xu C M. Simulation of the regeneration of a coked aromatization catalyst. Petroleum Science and Technology. 2009. 27(1): 96-110

Chen Z M, Gibilaro L G and Foscolo P U. Two-dimensional voidage waves in fluidized beds. Industrial \& Engineering Chemistry 
Research. 1999. 38(3): 610-620

Foscolo P U and Gibilaro L G. Fluid dynamics stability of fluidized suspensions: the particle bed model. Chemical Engineering Science. 1987. 42(6): 1489-1500

Gibilaro L G. Fluidization Dynamics. London: Butterworth Heinemann. 2001. 42-47

Guo B S, Wang R and Li Y H. The performance of solid phosphoric acid catalysts and macroporous sulfonic resins on gasoline alkylation desulfurization. Fuel Processing Technology. 2010. 91(11): 17311735

Hommeltoft S I. Isobutane alkylation: Recent developments and future perspectives. Applied Catalysis A: General. 2001. 221(1-2): 421428

Knowlton T M, Karri S B R and Issangya A. Scale-up of fluidized-bed hydrodynamics. Powder Technology. 2005. 150(2): 72-77

Li J H, Ouyang J, Gao S Q, et al. Multi-scale Simulation of Particle-fluid Complex Systems. Beijing: Science Press. 2005 (in Chinese)

Hu L Y, Zhang Z K, Xie S J, et al. Effect of grain size of zeolite Y on its catalytic performance in olefin alkylation thiophenic sulfur process. Catalysis Communications. 2009. 10(6): 900-904

Li Q, Zhang Y, Cao Z J, et al. Influence of synthesis parameters on the crystallinity and $\mathrm{Si} / \mathrm{Al}$ ratio of $\mathrm{NaY}$ zeolite. Petroleum Science. 2010. 7(3): 403-409

Meister J M, Black S M and Muldoon B S, et al. Optimize alkylates production for clean fuels. Hydrocarbon Processing. 2000. 79(5): 63-64, 66, 69-70, 72-75

Nieto O, Niño M, Martínez R, et al. Simulation of a spouted bed reactor for solid catalyst alkylation. Fuel. 2007. 86(9): 1313-1324

Pan H F, Liu X Y, Wei G Y, et al. Synthesis of La-modified ultra stable zeolite $\mathrm{L}$ and its application to catalytic cracking catalyst. Petroleum Science. 2007. 4(2): 75-81
Patil D J, van Sint Annaland M and Kuipers J A M. Critical comparison of hydrodynamic models for gas-solid fluidized beds-Part I: Bubbling gas-solid fluidized beds operated with a jet. Chemical Engineering Science. 2005a. 60(1): 57-72

Patil D J, van Sint Annaland M and Kuipers J A M. Critical comparison of hydrodynamic models for gas-solid fluidized beds-Part II: Freely bubbling gas-solid fluidized beds. Chemical Engineering Science. 2005b. 60(1): 73-84

Pei P, Zhang K, Lu E W, et al. CFD simulation of bubbling and collapsing characteristics in a gas-solid fluidized bed. Petroleum Science. 2009. 6: 69-75

Platon A and Thomson W J. Solid acid characteristics and isobutane/ butene alkylation. Applied Catalysis A: General. 2005. 282(1-2): 93100

Song C. An overview of new approaches to deep desulfurization for ultra-clean gasoline, diesel fuel and jet fuel. Catalysis Today. 2003. 86(1-4): 211-263

Tailleur R G. Simulation of three-phase spouted bed reactor for solid catalyst alkylation. Chemical Engineering and Processing: Process Intensification. 2008. 47(8): 1390-1403

Wang Q C, Zhang K and Gu H Y. CFD simulation of pressure fluctuation characteristics in the gas-solid fluidized bed: comparisons with experiments. Petroleum Science. 2011. 8: 211-218

Wang Y, Xu C M, Gao J S, et al. Distribution of solid flow rate and loading in liquid-solid loop reactor. Chemical Reaction Engineering and Technology. 2003. 19(3): 284-288 (in Chinese)

Zhang K, Brandani S and Bi J. Computational fluid dynamics for dense gas-solid fluidized beds. Progress in Natural Science. 2005. 15(special issue): 43-52 